\title{
A categoria território na política de assistência social: notas sobre desigualdade territorial e o acesso aos bens e serviços públicos
}

\author{
The territory category in social assistance policy: notes on territorial inequality and access to \\ public goods and services
}

\author{
Daniely Silva de Viveiros* \\ Gustavo Leite Araujo da Silva** \\ Diana Jenifer Ribeiro de Almeida***
}

\begin{abstract}
Resumo:
O presente trabalho realiza uma análise crítica da Política Nacional de Assistência Social (PNAS), procurando estabelecer uma aproximação das categorias de território e acesso, tanto em sua base normativa quanto na prática de planejamento e gestão desta política. Este trabalho objetiva qualificar dois aspectos principais: a definição dos direitos sociais e do acesso aos bens e serviços públicos no contexto brasileiro e como a categoria território emerge como elemento norteador da política de assistência social. A partir deste modelo desenha-se o cerne da discussão e questões objetivas a serem desenvolvidos: como se constituíram as noções de acesso aos direitos sociais e território na PNAS? A implantação da política de assistência social, a partir da aprovação da PNAS, em 2004, pode ou não contribuir na superação das formas de exclusão decorrentes do processo de espoliação urbana e de desigualdades socioterritoriais, já que não há universalização do atendimento e de direitos sociais ao público a que se destina esta política?
\end{abstract}

Palavras-chave: Políticas públicas. Assistência social. Território. Direitos sociais. Desigualdade socioterritorial.

\begin{abstract}
:
This paper presents a critical analysis of the National Social Assistance Policy (PNAS), seeking an approximation of the categories of territory and access, both in its normative basis and in the planning and management practice of this policy. This paper aims to qualify two main aspects: the definition of social rights and access to public goods and services in the Brazilian context and as an emerging territory category as a guiding element of social assistance policy. From this model, we draw or deal with discussions and objective questions to be used: how are they constituted as notions of access to social rights and territory in PNAS? The implementation of the social assistance policy, after PNAS approval, in 2004, may or may not contribute to overcoming the forms of prohibition against the use of urban spoliation processes and socio-territorial inequalities, since there is no universalization of care and rights?
\end{abstract}

Keywords: Public policy. Social assistance. Territory. Social rights. Socio-territorial inequality.

\footnotetext{
* Assistente social na Secretaria Municipal de Assistência Social e Direitos Humanos da Prefeitura da Cidade do Rio de Janeiro, mestranda em Políticas Públicas e Formação Humana na Universidade do Estado do Rio de Janeiro - UERJ.

** Geógrafo, Professor na Prefeitura Municipal de Magé, mestrando em Políticas Públicas e Formaação Humana na Universidade do Estado do Rio de Janeiro - UERJ

*** Psicóloga, Professora na UNIFESO - RJ, Doutora em Psicologia Social na Universidade do Estado do Rio de Janeiro - UERJ
} 


\section{Introdução}

A assistência social é a política pública destinada a "garantir a todos, que dela necessitam, e sem contribuição prévia, a provisão dessa proteção" (MINISTÉRIO DO DESENVOLVIMENTO SOCIAL, 2005, p. 15). Tem como diretrizes estruturantes a primazia da responsabilidade do Estado na sua condução, bem como a territorialização, prevendo a necessidade de reconhecimento da amplitude e diversidade que configuram a realidade nacional. Apesar do reconhecimento na Constituição federal de 1988 (CF/88), o avanço em uma sistematização de normas e fortalecimento institucional só se efetivou no século XXI. Seus principais aparatos normativos são a Lei Orgânica de Assistência Social (LOAS), de 1993, a Política Nacional de Assistência Social (PNAS), de 2004, a Tipificação Nacional dos Serviços Socioassistenciais, de 2009, as Normas Operacionais Básicas do Sistema Único de Assistência Social (NOB/SUAS), de 2005 e 2012, e a Lei no 12.435 ("Lei do SUAS"), de 2011.

A PNAS estabelece a perspectiva socioterritorial para seu planejamento e execução, trazendo o foco para identificação e atendimento de setores populacionais tradicionalmente excluídos e apartados do campo dos direitos sociais. Ao agir nas capilaridades dos territórios e se confrontar com a dinâmica do real e no campo das informações, essa política pretende inaugurar uma outra perspectiva de análise ao tornar visíveis aqueles setores da sociedade brasileira tradicionalmente tidos como invisíveis ou excluídos das estatísticas - população em situação de rua, adolescentes em conflito com a lei, indígenas, quilombolas, idosos, pessoas com deficiência (MINISTÉRIO DO DESENVOLVIMENTO SOCIAL E COMBATE À FOME, 2005, p. 16).

A categoria território emerge como elemento norteador da política de assistência social na PNAS, mesclando ora a noção de um recorte político-territorial, ora a noção de um espaço social marcado por situações de vulnerabilidade social e expressão de desigualdade. Ao território agrega-se a possibilidade de acesso aos bens e serviços públicos. No entanto, de acordo com o geógrafo Milton Santos, há uma histórica desigualdade na distribuição espacial de bens e serviços públicos no território, agravados por uma precariedade ou restrição de acesso a tais bens.

De um modo geral, as políticas sociais lidam com o acesso como ponto de partida para sua elaboração e implementação, o que se leva à necessidade de qualificar dois aspectos 
principais: a definição dos direitos sociais (e de cidadania) e do acesso aos bens e serviços públicos no contexto brasileiro.

\section{Os direitos sociais e o acesso aos bens e serviços públicos no Brasil}

Há uma relação direta entre os conceitos de cidadania e direitos sociais e a questão do acesso aos bens de serviços públicos. Neste aspecto, cabe a discussão acerca da constituição e acesso aos direitos no Brasil, marcados por profundas desigualdades e pela consolidação de uma gama de excluídos em diferentes tempos históricos, revelando que a igualdade em termos de direitos civis, políticos e sociais sempre foi fator questionável na história brasileira.

Telles (1999) salienta que os direitos sociais se reconhecem no rol dos direitos humanos, e são relativos a todos os indivíduos, sem nenhuma distinção:

[...] desde a Declaração Universal dos Direitos Humanos, da ONU em 1948, os direitos sociais foram reconhecidos, junto com os direitos civis e os direitos políticos, no elenco dos direitos humanos: direito ao trabalho, direito ao salário igual por trabalho igual, direito à previdência social em caso de doença, velhice, morte do arrimo de família e desemprego involuntário, direito a uma renda condizente com uma vida digna, direito ao repouso e ao lazer (aí incluindo o direito às férias remuneradas), e o direito à educação (p. 173).

Ao tecer as noções de direitos e cidadania no campo das lutas e do conflito para a construção de uma sociedade e igualitária, Telles (2001) interpõe o caso brasileiro com o fato de que os direitos proclamados não são traduzidos em ação igualitária. Segundo a autora,

[...] paradoxos na mesma sociedade. Não pela evidência do descompasso entre a existência formal dos direitos e a realidade da destituição das maiorias, ou melhor, pelo que esse descompasso revela da lógica que presidiu a formulação e formalização dos direitos na sociedade brasileira. Pois o que chama a atenção é a constituição de um lugar em que a igualdade prometida pela lei reproduz e legítima desigualdades; um lugar que constrói dentro dele próprio o princípio que exclui as maiorias; um lugar que proclama a realização da justiça social, mas bloqueia os efeitos igualitários dos direitos na trama das relações sociais" (TELLES, 2001, p.24).

Nesta lógica, o conceito de "cidadania regulada" de Wanderley Guilherme dos Santos (1979) localiza o desenvolvimento da cidadania no Brasil dentro de um sistema de estratificação ocupacional, consolidado a partir de categorias profissionais regulamentadas pelo Estado, estabelecendo, desta forma, a diferenciação de acesso aos serviços e benefícios. O cidadão seria aquele não somente inserido no mercado de trabalho, mas com a profissão regulamentada. Muito se vê desta herança na conformação dos direitos sociais no Brasil, 
entretanto, historicamente amplas parcelas da população tiveram uma inserção marginal no mercado de trabalho, significando o subemprego e a informalidade.

Como demonstra Francisco de Oliveira, em "Os direitos do antivalor" (1998), a integração no mercado de trabalho em toda a América Latina se deu pela exclusão: negros, índios, crianças, mulheres, entre outros, aumentando a massa de pobres na região. Segundo ele, a informalização é um processo da própria industrialização, e associado a isso "o Estado se funcionaliza como uma máquina de arrecadação para tornar o excedente disponível para o capital. E a exceção está em que as políticas sociais não têm mais o projeto de mudar a distribuição de renda" (OLIVEIRA, 2000, p. 11). Nesta direção, Milton Santos (2014) define os "desiguais sem remédio" e "desiguais institucionais": negros, nordestinos, mulheres (p. 32).

Discorrer sobre a cidadania no Brasil exige a contextualização da desigualdade estrutural e, em decorrência disto, a diferenciação de acessos aos direitos. A associação entre cortes profundos no investimento e gasto social e altas taxas de desemprego faz não só acirrar o reflexo das desigualdades, como desproteger centenas de milhares de brasileiros, que historicamente já tem a proteção social fragilizada em decorrência da enfraquecida ordem jurídica que garantiria tal proteção. Desde a década de 90, o país sofre "rodadas de neoliberalização", conforme qualifica Brandão (2017), que, apesar do avanço do conjunto de políticas sociais no período de 2003 e 2015, foram caracterizadas por um processo contraditório e simultâneo de produção de cidades, marcadas por urbanização precarizada e destituição de direitos para a população.

Kowarick (1991) traz a importante reflexão de como as políticas sociais exercem um importante papel em reforçar as ausências e precariedade na condição de vida de brasileiros. O conceito de espoliação urbana formulado pelo autor, ainda na década de 70 (KOWARICK, 1983) oferece a chave na avaliação de como as condições de vida da população estão diretamente associadas à ausência ou precariedade de acesso aos bens e serviços públicos em decorrência do caráter histórico e conjuntural da dinâmica econômica vigente no país. Kowarick defende que:

[...] a reprodução da força de trabalho não é apenas a materialidade objetiva que decorre primordialmente do processo de venda da força de trabalho e do seu desgaste, que no caso das cidades supõe também o acesso aos bens de consumo coletivo [...] Retomar a noção de espoliação urbana pode servir para esclarecer o processo de produção de um discurso sobre uma exclusão social. Ela se refere, incialmente à ausência ou precariedade de serviços de consumo coletivos que, como acesso à terra e à habitação, se mostram socialmente necessários à reprodução 
urbana dos trabalhadores. A ideia aí contida é que não só existe necessidade de ter acesso à água encanada ou ruas pavimentadas, aulas de matemática, exames cardiológicos ou endoscópicos, mas que trata- se de uma construção histórica que decorre das lutas sociais. [...] Neste sentido, a espoliação urbana só pode ser entendida como produção histórica que, ao se alimentar de um sentimento coletivo de exclusão, produz uma percepção de que algo - um bem material ou cultural - está faltando e é socialmente necessário. Desta forma, a noção contém a ideia de que o processo espoliativo resulta de uma somatória de extorsões, isto é, retirar ou deixar de fornecer a um grupo, categoria ou classe o que estes consideram como direitos seus (1991, p. 4, grifo nosso).

Para Kowarick (2009a) ocorre uma "fragilização da cidadania, entendida como perda ou ausência de direitos e como precarização de serviços coletivos que garantiam uma gama mínima de proteção pública para grupos carentes de recursos” (p. 76). Kowarick indica que a reprodução dos trabalhadores é mediatizada pelo Estado, que gera os bens de consumo coletivo essenciais à reprodução urbana dos trabalhadores, contudo, a configuração espacial da cidade e os diferentes graus de inclusão-exclusão no acesso aos benefícios denotam o processo de espoliação urbana, visto que há uma segregação socioeconômica e espacial em áreas desigualmente providas de bens e serviços (KOWARICK, 2009, p. 99). O conjunto de situações denominado espoliação urbana configura-se como uma:

[...] somatória de extorsões que se opera pela inexistência ou precariedade de serviços de consumo coletivo, que juntamente ao acesso à terra e à moradia apresentam-se como socialmente necessários para a reprodução dos trabalhadores e aguçam ainda mais a dilapidação decorrente da exploração do trabalho ou, o que é pior, da falta desta (KOWARICK, 2009, p. 22).

Ao se associar o acesso aos direitos materializados enquanto bens de consumo coletivo, avaliou-se o papel do Estado em provê-los, bem como de promover a universalização de tais direitos. A ação estatal, desta forma, gera bens e serviços que se tornam elementos indispensáveis para a reprodução da força de trabalho e a consequente expansão do capital.

Para Garza (2015), "os meios de consumo coletivo estão constituídos pelo equipamento indispensável para a reprodução da força de trabalho ou, se se prefere, para fazer menos ingrata a vida da população" (GARZA, 2015, p. 51). O autor indica que os meios de consumo coletivo são constituídos pela moradia pública, fornecimento de água e eletricidade, assim como o equipamento e seus serviços correspondentes de saúde, educação, cultura e lazer. Incluímos, neste caso, os equipamentos de assistência social.

No cenário de desmonte e depreciação dos direitos sociais, os bens de consumo coletivo seguem uma tendência de esgotamento, seja pela ausência ou insuficiência para 
atendimento da população, seja pelo processo de privatização de parte destes serviços, como no caso da educação e da saúde. Fato é que com as "rodadas de neoliberalização" sofridas desde a década de 90, uma parcela maior dos serviços privados teve ampliação em número e em regulação, efetivando seu pleno funcionamento e expansão. Cardoso Junior (2018) alerta para a tendência pós-década de 1990 de participação do setor privado na provisão de proteção social, associada à "universalização restrita", tanto na cobertura e quanto no atendimento das políticas de saúde, educação, saúde, assistência e previdência social.

Nesta direção, Milton Santos (2014) alerta

[...] que onde os bens sociais existem apenas na forma mercantil, reduz-se o número dos que potencialmente lhes tem acesso, os quais se tornam ainda mais pobres por terem que pagar o que, em condições democráticas normais, teria de lhe ser entregue gratuitamente pelo poder público (p. 144).

O lugar onde uma pessoa está implica no tipo de acesso aos serviços, pois requer que a oferta seja a uma distância e localização acessível, o que determina o efeito que a distribuição espacial da oferta tem sobre a desigualdade.

\section{A categoria território e a distribuição territorial dos bens e serviços públicos como determinante de acesso}

A categoria território historicamente se constitui na relação entre poder e Estado, atravessada por contradições e conflitos que revelam uma tensão permanente mesmo anteriormente à formação do Estado Moderno. Pela diversidade e conflitualidade das relações de perpassam o território, ele não está retido em uma definição de delimitação ou função espacial, mas pelas implicações políticas, sociais e econômicas destas relações que nele se estabelecem. Nascimento e Melazzo (2013) indicam uma perspectiva polissêmica do território, em que "possa ser compreendido enquanto apropriação social, com diferentes nuances - culturais, políticas e econômicas" (p. 82).

Silva (2013) faz uma análise da categoria por meio de diferentes abordagens, chegando a uma sistematização que congrega a multidimensionalidade do território:

[...] pode-se estabelecer uma definição sintética de território como um espaço de construção social e poder instituído (porém não imutável), caracterizado por recursos físicos específicos (naturais e industriais) e valores (históricos e culturais) que estabelecem elementos de identidade aos sujeitos que nele habitam. Considera- 
se também que o território é formado tanto por lugares contíguos (relações de vizinhança) como por lugares em rede (processos sociais que ligam lugares diferentes). Sob este entendimento, o território constitui uma base flexível sobre a qual agem distintas forças endógenas e exógenas, de maneira que este se encontra continuamente submetido a relações de poder (conflitivas e/ou cooperativas) nos processos históricos de apropriação e dominação do território, bem como a pressões por mudanças, que podem implicar expansão ou deslocamento (SILVA, 2013, p. 553).

$\mathrm{Na}$ constituição da categoria território, portanto, é necessário correlacionar as dimensões política e econômica, considerando-o enquanto construção histórica e social que modifica, condiciona, amplia e configura o espaço, por meio da intervenção permanente de instituições e pessoas e das respectivas relações sociais que ali se desenvolvem.

Para Milton Santos, o território, como base da vida social, deve ser entendido enquanto território usado, dada a complexidade de relações que nele se estabelece:

\footnotetext{
O território não é apenas o resultado da superposição de um conjunto de sistemas naturais e um conjunto de sistemas de coisas criadas pelo homem. $O$ território é o chão e mais a população, isto é, uma identidade, o fato e o sentimento de pertencer àquilo que nos pertence. $O$ território é a base do trabalho, da residência, das trocas materiais e espirituais e da vida, sobre os quais ele influi. Quando se fala em território deve-se, pois, de logo, entender que se está falando em território usado, utilizado por uma dada população. Um faz o outro, à maneira da célebre frase de Churchill: primeiro fazemos nossas casas, depois elas nos fazem... A ideia de tribo, povo, nação e, depois, de Estado nacional decorre dessa relação tornada profunda (SANTOS, 2015, p. 96).
}

Na constituição normativa da assistência social o território é apontado como espaço privilegiado de intervenção e base de organização do Sistema Único de Assistência Social (SUAS). A partir de 2004 a categoria território se fez presente em todas as instâncias da política, fazendo-se representar nos discursos dos profissionais e gestores da área da assistência social: no reconhecimento do território de atuação, de ocorrência de vulnerabilidades e riscos, de implantação de equipamentos assistenciais. Desta forma, a política de assistência social adquiriu um status de "reconhecedora" das desigualdades e potencialidades que retratariam o lócus de atuação em todos os municípios do Brasil, de maneira a considerar as complexidades inerentes a cada um desses locais.

Para fins desta análise, foi considerado a PNAS como um documento inaugural do uso do termo território com a conotação que ultrapassaria a delimitação de um espaço geográfico, ainda que seja questionável as formas de expressão em que o termo aparece no documento. Para além da PNAS, as NOB-SUAS, 2005 e 2012, e a Lei no 12.435/11 seriam documentos normativos importantes na análise do termo. 
O termo território, trazido da geografia para o campo da assistência social, apresentase enquanto categoria que pode ser analisada e configurada de acordo com diferentes matizes, segundo aponta Koga (2003), que parte da análise de Milton Santos, para discutir o "território como chão concreto das políticas, a raiz dos números e a realidade da vida coletiva" (KOGA, 2003, p. 33).

Na PNAS, o território é referenciado ao Milton Santos, ainda que na perspectiva apresentada haja um contraste persistente entre a denominação do território enquanto uma área de delimitação espacial e enquanto a categoria território usado, configurado pelas relações sociais, econômicas e políticas e constituído historicamente como um espaço de vivências, trocas, bem como de tensões e conflitos. Na PNAS, a menção de termos como "território nacional", "território de fronteira", "território brasileiro" contrastam com os termos de território relacionados às situações de vulnerabilidade, risco e precariedade. A PNAS direciona que o público usuário e as características de seu lugar de vida sejam ponto de partida de planejamento e intervenção na política de assistência social, reconhecendo que é a partir do território que deve ser organizado o SUAS e uma "política de Proteção Social no Brasil” (MINISTÉRIO DO DESENVOLVIMENTO SOCIAL E COMBATE À FOME, 2005, p. 59).

Considerando a alta densidade populacional do País e, ao mesmo tempo, seu alto grau de heterogeneidade e desigualdade socioterritorial presentes entre os seus 5.561 Municípios, a vertente territorial faz-se urgente e necessária na Política Nacional de Assistência Social. Ou seja, o princípio da homogeneidade por segmentos na definição de prioridades de serviços, programas e projetos torna-se insuficiente frente às demandas de uma realidade marcada pela alta desigualdade social. Exige-se agregar ao conhecimento da realidade a dinâmica demográfica associada à dinâmica socioterritorial em curso.

Também, considerando que muitos dos resultados das ações da política de assistência social impactam em outras políticas sociais e vice-versa, é imperioso construir ações territorialmente definidas, juntamente com essas políticas.

Importantes conceitos no campo da descentralização foram incorporados a partir da leitura territorial como expressão do conjunto de relações, condições e acessos inaugurados pelas análises de Milton Santos, que interpreta a cidade com significado vivo a partir dos "atores que dele se utilizam" (MINISTÉRIO DO DESENVOLVIMENTO SOCIAL E COMBATE À FOME, 2005, p. 43).

A NOB-SUAS/2012, por sua vez, dá um passo importante ao definir a vigilância socioassistencial, que deve permitir não somente identificar a demanda e oferta de serviços socioassistenciais, mas a leitura de vulnerabilidades, riscos e violações que possam direcionar a ação da política de assistência social. Como documento normativo orientador de papéis dos entes federativos, do financiamento e das principais linhas de ação, a NOB-SUAS/2012 não 
Daniely Silva de Viveiros, Gustavo Leite Araujo da Silva, Diana Jenifer Ribeiro de Almeida

discorre sobre a categoria território, nem dá pistas sobre as contradições, diferenças e desigualdades socioterritoriais presentes nas regiões e municípios brasileiros.

A Lei $n=12.435 / 2011$ estabelece que o SUAS, com seus objetivos, tem como base de organização o território. Na Lei, a vigilância socioassistencial deve identificar os agravos ocorridos em um território, e o CRAS é o equipamento de base territorial que deve articular os demais serviços socioassistenciais em seu "território de abrangência".

A utilização do território como base de organização e atuação da política de assistência social traz a necessidade de dimensionar qual a relação das políticas públicas e, especificamente, das políticas sociais com a população atendida. A multiplicidade de fatores que atravessam o cotidiano de vida dessas pessoas ao transformá-las em "público-alvo" da assistência social tem uma relação direta com a configuração do território enquanto a categoria proposta por Milton Santos: o território usado, com os homens e suas relações, possui um conteúdo social, com contradições e como um campo de forças "entre o vertical e o horizontal, entre o Estado e o mercado, entre o uso econômico e o uso social dos recursos (SANTOS, 1999, p. 19).

O entendimento do território usado, enquanto lugar tanto de desigualdades quanto de potencialidades e solidariedade ultrapassa em muito a leitura do território enquanto mero espaço de intervenção ou base de organização de um serviço. "O território é o lugar em que desembocam todas as ações, todas as paixões, todos os poderes, todas as forças, todas as fraquezas, isto é, onde a história do homem plenamente se realiza a partir das manifestações da sua existência" (SANTOS, 2011, p. 12). Passados 15 anos do advento da PNAS, como a categoria território usado foi efetivamente incorporada à política de assistência social, em um contexto de agravamento de desigualdades e aumento das situações de vulnerabilidade social no país?

Ribeiro (2013) ressalta que o planejamento do território deve incluir o

[...] reconhecimento de vínculos concretos entre: necessidades básicas, pressupostos materiais da economia e a sua manifestação ao nível das prioridades políticas. [...] A prática do planejamento instala-se-como gestão política de recursos - entre as desigualdades da estrutura da sociedade e as condições imediatas da vida coletiva, fortemente influenciadas pela busca da legitimidade por interesses e segmentos sociais (RIBEIRO, 2013, p. 118).

Isto leva diretamente ao fator objetivo relacionado às desigualdades territoriais a que se refere Milton Santos. A utilização da categoria território usado de Milton Santos não deve abster-se do reconhecimento da existência de "cidadãos desiguais" ou "cidadãos diminuídos, 
incompletos" (SANTOS, 2014), já que esta é uma variável presente nos questionamentos elaborados pelo geógrafo em boa parte de sua obra, associando o acesso das pessoas ao lugar onde vivem: o componente territorial define uma política efetivamente redistributiva.

\section{O território, descentralização e desigualdades socioterritoriais}

O território usado, categoria citada na PNAS, é de extrema relevância para o campo das políticas públicas, dada a necessidade de construção de parâmetros de análise e implementação de políticas que incorporem a dialética e diferentes mediações inerentes aos territórios. O estágio de formulação da política de assistência social, por exemplo, assim como das demais políticas públicas, deve prever seus impactos na redução das situações de vulnerabilidade do público, e os estudos das características territoriais podem e devem representar a multiplicidade de fatores que influenciam a vida das pessoas atendidas.

Conforme indica Gatica (2013), "a multiplicidade de problemas sociais sobrepõe uma multiplicidade de características territoriais que impactam nas possibilidades de um programa de atender de maneira equilibrada às demandas e necessidades das comunidades e famílias" (p. 4). Dentre tais características, está a capacidade de gestão institucional e articulação que se fazem presentes neste território, que pressupõem a existência de ativos a que podem recorrer a população, como a rede socioassistencial, oferta de empregos, serviços de saúde, educação, entre outros.

No panorama das políticas sociais, a identificação das diversas problemáticas que entremeiam o cotidiano de vida das famílias deve ser necessariamente um ponto de partida tanto no que concerne à construção dos diagnósticos para proposição e financiamento de ações, quanto para a correspondência de efetividade exigida na administração pública no manejo de tais problemáticas. A ação governamental estabelece parâmetros de atuação que elegem e privilegiam certos recortes territoriais como parte preponderante do desenho de intervenção das políticas públicas.

Política e território, portanto, formam um par dialético indissociável e influenciamse mutuamente, de forma que a organização do território é resultante direta das decisões políticas, que, em geral, são delineadas segundo as estratégias de reprodução das relações sociais de produção e a lógica e interesses das classes dominantes e hegemônicas (OLIVEIRA; SOARES, 2012, p. 6). 
Este cenário supõe que na perspectiva territorial a existência do diálogo entre os atores e níveis de governo constitua uma interface de atuação coadunada com a vivência da população, suas ausências e potencialidades. Neste sentido, Lindo (2015) frisa o papel do Estado enquanto promotor de uma rede de atenções que assegure a dignidade humana, frente ao cenário de violação constante das necessidades sociais básicas no modo de produção capitalista, expressado por meio da desigualdade socioespacial, e a política social deve ser o meio pelo qual o Estado assegure tais necessidades na produção do espaço. Logo, o papel do Estado no ordenamento territorial e no planejamento das políticas públicas indica que os agentes públicos envolvidos nestes aspectos precisam trabalhar em uma perspectiva articuladora de recursos e responsabilidades dos diferentes níveis governamentais (OLIVEIRA, 2014).

Silva (2013) faz uma análise de como a categoria território foi apropriada pelo Estado em diferentes espaços de intervenção nas políticas públicas, dentro de um cenário de profundas desigualdades sociais e federativas (p. 554). Um dos principais entraves foi como se deu o processo de descentralização a partir da década de 90 , desconsiderando as diferenciações e distintas carências das unidades federativas, o que reforçou o cenário de desigualdades já existentes, acirrada por uma falta de coordenação política e federativa, reforçando ao superposição de arenas de negociação, coordenação e ação das políticas, bem como das desigualdades territoriais na provisão dos serviços nos diversos entes federados (SILVA, 2013, p. 555). Embora avanços sejam detectados, perdura uma dispersão de iniciativas das políticas públicas, prejudicando a integração entre elas no nível territorial. Como uma possibilidade de rompimento com este impasse, há a necessidade de construção integrada entre os entes federativos e agentes das políticas públicas na formulação e execução, com respeito às ações descentralizadas nos territórios.

Favareto e Lotta (2013) destacam que "a lógica intersetorial pressupõe a articulação e junção de diferentes ações com um foco específico, seja um território onde se quer atuar seja um público alvo bem definido ou um problema complexo que se deseje enfrentar" (p. 5). Ainda segundo eles, a intersetorialidade será definida da maneira como a organização horizontal de programas ou ações permitam uma efetiva integração entre eles. No país, a intersetorialidade tem graus e formas bastante distintas, desde incorporação nos processos de formulação das políticas públicas, ou apenas no monitoramento de ações de um mesmo tema, sem que haja uma concreta integração entre as políticas. Conforme defendido por 
Favareto e Lotta (2013), uma variável central da intersetorialidade e seus arranjos institucionais são justamente as relações federativas e de como estas se relacionam no processo de formulação e execução da política de assistência social. Este é um ponto bastante delicado na política de assistência social, em vista de que há uma disparidade entre o processo de formulação da política e a sua execução, realizada pelos municípios.

A partir da $\mathrm{CF} / 88$, com a orientação de descentralização político administrativa, houve uma reconfiguração do papel do município enquanto órgão executor de diversas políticas, sobretudo as sociais, se constituindo como ente federado. O modelo brasileiro implica uma repartição de responsabilidade entre os entes federados, ou seja, desenha um quadro institucional em que se estabelece uma delimitação das competências da União, estados e municípios.

Em Estados federativos, estados e municípios - porque dotados de autonomia política e fiscal - assumem funções de gestão de políticas públicas ou por própria iniciativa, ou por adesão a algum programa proposto por outro nível mais abrangente de governo, ou ainda por expressa imposição constitucional. Assim, a transferência de atribuições entre níveis de governo supõe a adesão do nível de governo que passará a desempenhar as funções que se pretende que sejam transferidas. A recuperação das bases federativas do Estado brasileiro tem impacto sobre o processo de descentralização das políticas sociais no país pelo fato de que, resguardados pelo princípio da soberania, estados e/ou municípios assumem a gestão de políticas públicas sob a prerrogativa da adesão, precisando, portanto, ser incentivados para tal (ARRETCHE, 1999, p.114).

A transferência de responsabilidades entre os entes federados demanda a adesão do nível de governo que desempenhará as funções que serão transferidas. A partir da década de 1990 foram construídos mecanismos para que governos locais passem a aderir políticas públicas desenvolvidas no âmbito federal.

Ao partir das formulações de Marta Arretche (2012), Favareto e Lotta registram, ademais, a limitação de autonomia dos governos locais nas tomadas de decisão, a despeito de sua autonomia política. Mesmo com a afirmação da gestão compartilhada e do respeito aos níveis de gestão, a assistência social é baseada pelo controle excessivo do governo federal, sobretudo atrelado ao repasse de recursos, o que cria, na verdade, uma pretensa padronização dos serviços, mas que se inviabiliza a limitação financeira e operacional dos municípios brasileiros.

Junto à intersetorialidade e às relações federativas, Favareto e Lotta (2013) assinalam a dimensão territorial como aspecto a ser diretamente relacionado à gestão e implementação 
de políticas públicas, ocasionando, em muitos casos, indicadores diferenciados das políticas nacionais, o que sugere, segundo os autores, que os fatores locais condicionam o êxito dos investimentos, assim como as limitadas capacidades institucionais de pequenos municípios e a necessidade de mobilização de diferentes forças sociais em algumas políticas públicas.

A principal questão é que o "direito a ter direitos", parafraseando Hannah Arendt, se materializa não somente na formulação da política pública, mas, principalmente, na forma como ela se concretiza nos diferentes contextos e territórios na escala municipal. O poder local, neste caso, operaria não somente como o executor da política, mas como principal agente na identificação dos conflitos, manifestações e potencialidades presentes no território. Ao invocar a categoria território, a PNAS assume o âmbito municipal como a unidade de gestão e execução da política pública de assistência social, contemplando as possibilidades de reconhecimento e identificação de demandas e peculiaridades presentes nesta esfera. No entanto, observa-se um processo de centralização normatizadora, que fere o próprio requisito de valorização da esfera local e da territorialização defendida pela PNAS, em que, apesar do SUAS ser conceituado como descentralizado e participativo, estes termos reduzem a escala local geralmente a uma função de executora da política, criando uma cisão entre a formulação (policy-decision making) central e a sua execução local (policy making) ${ }^{1}$. Neste sentido, recorre-se à Arretche (2012), que defende:

A distinção analítica entre quem regula (policy decision-making) e quem executa (policy-making) é essencial para examinar a propalada autonomia dos governos subnacionais no Brasil. A interpretação de que estes são excessivamente autônomos está baseada na indistinção conceitual entre policy-making e policy decision-making. Assume-se que os governos subnacionais têm autonomia sobre suas próprias políticas porque sua execução foi descentralizada e porque governos subnacionais têm uma participação importante na receita e nos gastos nacionais. A distinção conceitual entre "quem delibera" e "quem executa" autoriza interpretação distinta acerca dos mecanismos verticais de operação do Estado federativo brasileiro. A regulação federal afeta decisivamente o modo como as políticas descentralizadas são executadas. As regras constitucionais, a autoridade dos ministérios federais para regulamentar e supervisionar as políticas executadas, bem como o poder de gasto da União, são fatores explicativos centrais da agenda dos governos subnacionais ( $p$. 20).

A política de assistência social no Brasil tem como um de seus objetivos previstos na Lei 12.435/11: "para o enfrentamento da pobreza, a assistência social realiza-se de forma integrada às políticas setoriais, garantindo mínimos sociais e provimento de condições para

\footnotetext{
${ }^{1}$ Arretche traz a seguinte definição: quem regula (policy decision-making) e quem executa (policy-making) (2012, p. 19).
} 
atender contingências sociais e promovendo a universalização dos direitos sociais". Um dos questionamentos necessários a serem realizados é justamente o fato de promoção da universalização dos direitos sociais, quando nem mesmo a assistência social possui bases materiais e históricas para ampliação de seu próprio alcance.

A PNAS tem como uma de suas direções a ampliação do acesso aos serviços socioassistenciais e direitos sociais, sem, contudo, associar ao território a desigualdade espacial na distribuição dos bens públicos. Entende-se que esse fator causaria uma "implosão das bases" (TELLES, 2010) da política de assistência social. Isto porque, ao utilizar este termo, Vera da Silva Telles estabelece a articulação com a noção de "exceção permanente", recorrendo a Francisco de Oliveira, quando a política passa a administrar urgências, "que derroga as regras dos direitos, implode os contratos, desestabiliza os acordos e, sobretudo, desativa o espaço da política" (TELLES, 2010, p. 152).

Neste caso, pode-se traçar um paralelo com o papel dos Centros de Referência de Assistência Social (CRAS). Inscritos na Proteção Social Básica, estes equipamentos são a principal referência territorial, visto que têm o papel de

\begin{abstract}
[...] se articular com a rede de proteção social local no que se refere aos direitos de cidadania, mantendo ativo um serviço de vigilância da exclusão social na produção, sistematização e divulgação de indicadores da área de abrangência do CRAS, em conexão com outros territórios. Realiza, ainda, sob orientação do gestor municipal de Assistência Social, o mapeamento e a organização da rede socioassistencial de proteção básica e promove a inserção das famílias nos serviços de assistência social local. Promove também o encaminhamento da população local para as demais políticas públicas e sociais, possibilitando o desenvolvimento de ações intersetoriais que visem a sustentabilidade, de forma a romper com o ciclo de reprodução intergeracional do processo de exclusão social, e evitar que estas famílias e indivíduos tenham seus direitos violados, recaindo em situações de vulnerabilidades e riscos (MINISTÉRIO DO DESENVOLVIMENTO SOCIAL E COMBATE À FOME, 2005, p. 35, grifo nosso).
\end{abstract}

Foi avaliado que a PNAS atribui à unidade de referência mais capilarizada nos diferentes municípios uma responsabilidade de encaminhamento a políticas sociais sem dimensionar, necessariamente, o fato de que bens de consumo coletivo são desigualmente distribuídos, e observa-se que não é estabelecida a vinculação a uma acessibilidade aos bens e serviços. A PNAS associa os encaminhamentos para as políticas sociais à possibilidade de rompimento com o ciclo de exclusão social, de vulnerabilidade social e violações de direitos. Essa é uma missão que, no sentido de gerar acesso aos bens de consumo coletivo de modo 
ampliado, está em reverso, pois, mediante o desmonte de direitos no contexto atual de desenvolvimento do sistema capitalista e do neoliberalismo, há uma destituição das prerrogativas de cidadania embutidas em tal acessibilidade.

Como descrito até aqui, diversos são os percalços na constituição histórica dos direitos sociais no País, e uma parcela majoritária da população teve acesso apenas periférico ou insuficiente aos direitos sociais, que, quando materializados por meio das políticas sociais, nunca deixaram de enfrentar situações de desmantelamento e desqualificação, construindo um quadro de aumento da demanda por serviços na assistência social, ao passo que ela mesma sofre o mesmo desmantelamento das demais políticas.

Um ponto crucial a que se refere aqui é a necessidade de incorporar à categoria território, no planejamento e operacionalização das políticas, a dimensão da desigualdade territorial, que modifica e agrava sobremaneira o cenário de possibilidade de acesso da população aos bens e serviços públicos. Neste sentido, Milton Santos agrega em sua análise a gestão ao componente territorial, o que asseguraria a "distribuição geral dos bens e serviços públicos" (SANTOS, 2014, p. 18) e a instrumentação do território, o que atribuiria a todos os seus habitantes os bens e serviços indispensáveis, de modo a garantir a efetividade redistributiva da política pública e, portanto, da justiça social. Em “O Espaço do Cidadão" (2014), Santos encadeia a correlação entre os bens sociais e o acesso no território, delimitando o que ele define como "geografização da cidadania" (p. 150), associada aos direitos territoriais:

[...] mais do que um direito à cidade, o que está em jogo é o direito a obter da sociedade aqueles bens e serviços mínimos, sem os quais a existência não é digna. Esses bens e serviços constituem um encargo da sociedade, por meio das instâncias do governo, e são devidos a todos. Sem isso, não se dirá que existe o cidadão (SANTOS, 2014, p. 158).

O Estado tem um papel fundamental nesta desigualdade, já que, de forma geral, apoia por meio da política econômica e fiscal os grandes monopólios e corporações "em detrimento da população, particularmente das camadas mais desfavorecidas" (SANTOS, 2008, p. 161).

Lojkine (1981), em sua obra "O Estado capitalista e a questão urbana", discorre sobre a distribuição social e espacial desigual dos meios de consumo coletivos (p. 143). O autor estabelece a relação entre o valor de uso e do valor de troca dos equipamentos coletivos, sendo estes necessários para a reprodução e ampliação da força de trabalho, enquanto uma 
reprodução socializada, mas que acabam por ser comprimidas e definidas enquanto despesas supérfluas. Neste sentido, Kowarick (2009) destaca o Estado como um "agente ecumênico", cujas ações ao mesmo tempo favorecem a acumulação do capital e não excluem totalmente as classes trabalhadoras, visto que o acesso aos bens de consumo coletivo permitem a reprodução da força de trabalho para o capital, ainda que esse acesso seja "precário e residual" (p. 63).

Pelas análises referentes à categoria de território usado de Milton Santos e a sua associação com a distribuição territorial de bens e serviços públicos e, consequentemente, de justiça social, pode-se pressupor que as políticas sociais deveriam cumprir seu papel redistributivo em relação a localização de seus equipamentos públicos e a possibilidade de acesso da população. No Brasil há uma tensão entre a universalização e focalização de políticas sociais, o que se reflete estruturalmente na distribuição dos serviços pelo território. Apesar da expansão de serviços sociais públicos, principalmente a partir dos anos 2000 , ainda há um mapa de exclusão desenhado nas principais cidades brasileiras, agravados pela impossibilidade de acesso em decorrência de diversos fatores, principalmente relacionados à falta de infraestrutura, escassez de recursos financeiros e deficiências crônicas no sistema viário, e até mesmo a violência, o que afeta diretamente a população que vive nas periferias ou nas zonas mais remotas. Portanto, apesar da previsão de direitos contidas na $\mathrm{CF} / 88$, estes não se traduziram em direitos básicos acessados pela população em geral. Conforme ressalta Milton Santos (2014),

[...] o componente territorial supõe, de um lado, uma instrumentação do território capaz de atribuir a todos os habitantes aqueles bens e serviços indispensáveis, não importa onde esteja a pessoa; e, de outro lado, uma adequada gestão do território, pela qual a distribuição geral dos bens e serviços públicos seja assegurada. Nessas condições, deve-se falar de um modelo cívico-territorial, a organização e a gestão do espaço sendo instrumentais a uma política efetivamente redistributiva, isto é, tendente à atribuição de justiça social para a totalidade da população, não importa onde esteja cada indivíduo. (...) É no território, tal como ele atualmente é, que a cidadania se dá tal qual ela é hoje, isto é, incompleta. Mudanças no uso e na gestão do território se impõem, se queremos criar um novo tipo de cidadania, uma cidadania que se nos ofereça como respeito à cultura e como busca da liberdade. (SANTOS, 2014, p. 18, grifo nosso).

A concepção de acesso aos direitos restrita e excludente e a noção de distribuição territorial de bens e serviços, que no Brasil ainda demonstra ser desigual, conforme expõe Milton Santos, coloca em cheque a noção de universalidade de direitos e também um dos 
objetivos da política de assistência social, que é o enfrentamento da pobreza, por meio do "provimento de condições para atender contingências sociais e promovendo a universalização dos direitos sociais" (Lei 12.435/11). Desta maneira, um dos pilares de sustentação da PNAS e do SUAS, que é a categoria território, traz indagações além do seu uso, como defendido na política, mas de como historicamente os territórios e o acesso nas diferentes regiões e cidades brasileiras foram configurados, espelhando as situações de restrição ou negação de direitos a que são submetidas parcelas da população.

\section{Considerações finais}

Na PNAS não houve uma associação entre o acesso aos bens e serviços públicos e a concretização dos direitos sociais, ainda que a promoção da universalização de tais direitos esteja preconizada na política.

No Brasil, o acesso aos direitos sociais e aos bens e serviços públicos deles decorrentes se deu de forma desigual. No cenário de produção de uma massa de excluídos do mercado de trabalho, a informalidade virou regra, e as políticas sociais não deram conta dos aspectos contraditórios da relação entre acumulação e trabalho. De certa forma, as políticas sociais, de acordo com Kowarick (1991) reforçaram o cenário de precariedade das condições de vida da população, por meio da crescente desresponsabilização do Estado no provimento de bens de serviço coletivo, aprofundando a desigualdade de acesso em todo o País.

O panorama de extrema desigualdade territorial e de condições de espoliação urbana e descritos por Milton Santos e Lúcio Kowarick são parte constitutiva dos territórios, mas na política pública de assistência social permanecem recorrentes à conotação do recorte geográfico e administrativo, que, apesar do apelo do território usado e de suas relações, contradições, práticas e vínculos. Avalia-se que a gestão da política de assistência social não logrou incorporá-lo enquanto categoria central em seu planejamento, implementação e execução, isto no que se refere tanto à insuficiência ou ausência de recursos materiais e humanos, quanto à discrepância entre a formulação da política em nível federal - que centralizou historicamente os parâmetros de atuação - e o nível municipal, que o implementa e executa, mas está atrelado a um conjunto de condições técnicas e financeiras do nível federal.

Os aspectos até aqui apontados demonstram um duplo descolamento conceitual entre a formulação e a execução da PNAS: por um lado, a desconexão do acesso aos bens e 
serviços públicos como parte integrante da política, sem considerar as desigualdades territoriais como fator de exclusão social; por outro lado, a concepção da política valorizando o território e o protagonismo do município, com tônica nas ações descentralizadas, em contraposição a um forte aparto normativo centralizado operado pelo governo central.

A dimensão territorial só terá sua concretude enquanto meio garantidor e redistributivo da política pública quando o arranjo territorial efetivamente permita a acessibilidade aos bens e serviços a todos indivíduos, e, desta forma, possibilitando a materialização da cidadania. Apesar da afirmação normativa de igualdade de acesso, a desigualdade estrutural na distribuição territorial dos bens e serviços públicos, ou a "geografização da cidadania" para Milton Santos (2014), acirra a inequidade social e territorial.

\section{Referências}

ARRETCHE, M. T. S. Políticas sociais no Brasil: descentralização em um Estado federativo. Rev. Bras. Ciências Soc. [online]. 1999, vol.14, no 40, pp.111-141. Disponível em: http://www.scielo.br/pdf/rbcsoc/v14n40/1712.pdf. Acesso em: 13 de mar. 2019.

2012.

Democracia, federalismo e centralização no Brasil. Rio de Janeiro, FGV,

BRANDÃO, C. A. Crises e rodadas de neoliberalização: impactos nos espaços metropolitanos e no mundo do trabalho no Brasil. Cad. Metrop, São Paulo, v. 19, no 38, p. 45-69, jan/abr. 2017. Disponível em: http://www.scielo.br/pdf/cm/v19n38/2236-9996-cm-19-38-0045.pdf. Acesso em: 26 abr. 2019.

CARDOSO JUNIOR, J. C. P. A CF-1988 na Berlinda: trinta anos de disputas por um projeto nacional de desenvolvimento nos trópicos. Saúde Debate, v. 42, no especial 3, p. 18-32, nov. 2018. Disponível em: http://www.scielo.br/pdf/sdeb/v42nspe3/0103-1104-sdeb-42-spe030018.pdf. Acesso em: 25 jul. 2019.

FAVARETO, A. e LOTTA, G. S. O papel dos territórios nos novos arranjos institucionais brasileiros. XVIII Congreso Internacional del CLAD sobre la Reforma del Estado y de la Administración Pública, Montevideo, Uruguay, 29 oct. - 1 nov. 2013. Disponível em: https://cladista.clad.org/bitstream/handle/123456789/7420/0074905.pdf?sequence=1\&isAl lowed=y. Acesso em: 10 de agosto de 2018.

GARZA, G. Valor de los medios de consumo colectivo en la ciudad de Mexico. México, DF: El Colegio de México, Centro de Estudios Demográficos, Urbanos y ambientales, 2015. 
GATICA, M. I. F. Condiciones territoriales y acceso a la oferta pública de familias en situación de pobreza extrema. XVIII Congreso Internacional del CLAD sobre la Reforma del Estado y de la Administración Pública, Montevideo, Uruguay, 29 oct. - 1 nov. 2013.

LINDO, P. V. F. Uma Crítica Geográfica ao Conceito de Território na PNAS: por um diálogo entre Geografia e Serviço. Tese (doutorado) - Universidade Estadual Paulista, Faculdade de Ciências e Tecnologia. Presidente Prudente, 2015. $221 \mathrm{f}$.

KOGA, D. Medidas de cidades: entre territórios de vida e territórios vividos. São Paulo: Cortez, 2003.

KOWARICK, L. A espoliação urbana. São Paulo: Paz e Terra, 1983.

. Cidade e Cidadania - cidadão privado e subcidadão público. São Paulo em Perspectiva, São Paulo, no 2, p. 9-30, abril/junho de 1991.

. Escritos urbanos. 2ª ed. São Paulo: Editora 34, 2009.

Viver em risco: sobre a vulnerabilidade socioeconômica e civil. São Paulo:

Editora 34, 2009a.

LOJKINE, J. O Estado capitalista e a questão urbana. São Paulo, Martins Fontes, 1981.

MINISTÉRIO DO DESENVOLVIMENTO SOCIAL E COMBATE À FOME. Política Nacional de Assistência Social, PNAS/2004. Brasília: MDS, 2005.

Resolução CNAS no 130 de 15 de julho de 2005. Aprova a Norma Operacional Básica do Sistema Único de Assistência Social - NOB/SUAS. Brasília: CNAS, 2005.

- Resolução CNAS no 33 de 12 de dezembro de 2012. Aprova a Norma Operacional Básica do Sistema Único de Assistência Social - NOB/SUAS. Brasília: CNAS, 2009.

NASCIMENTO, P., MELAZZO, E. Território: conceito estratégico na assistência social. Serviço Social em Revista, v. 16, no 1, pp. 66-88, jul./dez. 2013. Disponível em: https://www.researchgate.net/publication/276231065 Territorio conceito estrategico na assistencia social. Acesso em: 02 jul. 2018.

OLIVEIRA, F. J. G. Território, Estado e políticas públicas territoriais: análise das políticas de gestão do território e da recente expansão/reconcentração econômica nos espaços metropolitanos. XIII Coloquio Internacional de Geocrítica El control del espacio y los espacios de control Barcelona, 5-10 de mayo de 2014. Disponível em: http://www.ub.edu/geocrit/coloquio2014/Floriano\%20Jose\%20Godinho\%20de\%200liveira. pdf. Acesso em: 10 abr. 2019.

OLIVEIRA, F. J. G.; SOARES, T. O. Os limites da integração e das políticas territoriais na escala local: a ação dos municípios no planejamento territorial. Scripta Nova. Rev. Electronica de Geografia y Ciencias Sociales, vol. XVI, no 418 (56). Barcelona, nov. 2012. Disponível em: http://www.ub.edu/geocrit/sn/sn-418/sn-418-56.htm. Acesso em: 13 abr. 2018. 
OLIVEIRA, F. Os direitos do antivalor - a economia política da hegemonia imperfeita. Petrópolis: Vozes, 1998.

- Passagem na neblina. In: OLIVEIRA, Francisco; STEDILE, João Pedro; GENOINO, José. Classes sociais em mudança e a luta pelo socialismo. São Paulo: Fundação Perseu Abramo, 2000. Disponível em: https://fpabramo.org.br/publicacoes/ estante/classessociais-em-mudanca-e-a-luta-pelo-socialismo/. Acesso em: 10 ago. 2018.

RIBEIRO, A. C. T. Por uma sociologia do presente: ação, técnica e espaço - Volume 3. Rio de Janeiro: Letra Capital, 2013.

SANTOS, M. O território e o saber local: algumas categorias de análise. Cadernos IPPUR, v. XIII, nㅇ 2, 1999.

- O espaço dividido: os dois circuitos da economia urbana dos países desenvolvidos. São Paulo: Editora da Universidade de São Paulo, 2008.

. O dinheiro e o território. In: SANTOS, Milton et al. Território, territórios: ensaios sobre o ordenamento territorial. Rio de Janeiro: Lamparina, 2011. 3a. ed.

. O espaço do cidadão. 7ạ ed. São Paulo: Editora da Universidade de São

Paulo, 2014.

. Por uma outra globalização. 25a ed. Rio de Janeiro: Editora da Record, 2015.

SANTOS, W. G. Cidadania e Justiça: a política social na ordem brasileira. Rio de Janeiro: Editora Campus, 1979.

SILVA, S. P. Considerações analíticas e operacionais sobre a abordagem territorial em políticas públicas. Políticas Sociais - acompanhamento e análise, no 21, Brasília, IPEA, 2013, p. 549-570. Disponível em: http://www.ipea.gov.br/portal/images/stories/PDFs/ politicas sociais/bps 21 artigoespecial.pdf. Acesso em: 24 jul 2019.

TELLES, V. S. Direitos Sociais: afinal do que se trata?. Belo Horizonte: Editora da UFMG, 1999. . Pobreza e Cidadania. São Paulo: USP/Ed.34, 2001.

. A cidade nas fronteiras do legal e ilegal. São Paulo: Argvmentvm, 2010.

Recebido em: 24.11.2019

Aceito em: 06.04.2020 